Article

\title{
Enhancement of Vindoline and Catharanthine Accumulation, Antioxidant Enzymes Activities, and Gene Expression Levels in Catharanthus roseus Leaves by Chitooligosaccharides Elicitation
}

\author{
Wenzhu Tang, Xiaoqi Liu, Yuning He and Fan Yang *
}

check for updates

Citation: Tang, W.; Liu, X.; He, Y.; Yang, F. Enhancement of Vindoline and Catharanthine Accumulation, Antioxidant Enzymes Activities, and Gene Expression Levels in Catharanthus roseus Leaves by Chitooligosaccharides Elicitation. Mar. Drugs 2022, 20, 188. https:/ / doi.org/10.3390/md20030188

Academic Editors: Jessica Amber Jennings and Joshua Bush

Received: 28 January 2022

Accepted: 2 March 2022

Published: 3 March 2022

Publisher's Note: MDPI stays neutral with regard to jurisdictional claims in published maps and institutional affiliations.

Copyright: (C) 2022 by the authors. Licensee MDPI, Basel, Switzerland. This article is an open access article distributed under the terms and conditions of the Creative Commons Attribution (CC BY) license (https:/ / creativecommons.org/licenses/by/ $4.0 /)$.
School of Biological Engineering, Dalian Polytechnic University, Dalian 116034, China; tangwz@dlpu.edu.cn (W.T.); liuxiaoqifighting@gmail.com (X.L.); he20220128@gmail.com (Y.H.) * Correspondence: yang_fan@dlpu.edu.cn; Tel./Fax: +86-411-86323646

\begin{abstract}
Catharanthus roseus (L.) G. Don is a plant belonging to the genus Catharanthus of the Apocynaceae family. It contains more than one hundred alkaloids, of which some exhibit significant pharmacological activities. Chitooligosaccharides are the only basic aminooligosaccharides with positively charged cations in nature, which can regulate plant growth and antioxidant properties. In this study, the leaves of Catharanthus roseus were sprayed with chitooligosaccharides of different molecular weights $(1 \mathrm{kDa}, 2 \mathrm{kDa}, 3 \mathrm{kDa})$ and different concentrations $(0.01 \mu \mathrm{g} / \mathrm{mL}, 0.1 \mu \mathrm{g} / \mathrm{mL}, 1 \mu \mathrm{g} / \mathrm{mL}$ and $10 \mu \mathrm{g} / \mathrm{mL}$ ). The fresh weights of its root, stem and leaf were all improved after chitooligosaccharides treatments. More importantly, the chitooligosaccharides elicitor strongly stimulated the accumulation of vindoline and catharanthine in the leaves, especially with the treatment of $0.1 \mu \mathrm{g} / \mathrm{mL} 3 \mathrm{kDa}$ chitooligosaccharides, the contents of them were increased by $60.68 \%$ and $141.54 \%$, respectively. Furthermore, as the defensive responses, antioxidant enzymes activities (catalase, glutathione reductase, ascorbate peroxidase, peroxidase and superoxide dismutase) were enhanced under chitooligosaccharides treatments. To further elucidate the underlying mechanism, qRT-PCR was used to investigate the genes expression levels of secologanin synthase (SLS), strictosidine synthase (STR), strictosidine glucosidase $(S G D)$, tabersonine 16-hydroxylase $(T 16 H)$, desacetoxyvindoline-4-hydroxylase $(D 4 H)$, deacetylvindoline-4-O-acetyltransferase (DAT), peroxidase 1 (PRX1) and octadecanoid-responsive Catharanthus AP2-domain protein 3 (ORCA3). All the genes were significantly up-regulated after chitooligosaccharides treatments, and the transcription abundance of ORCA3, SLS, STR, DAT and PRX1 reached a maximal level with $0.1 \mu \mathrm{g} / \mathrm{mL} 3 \mathrm{kDa}$ chitooligosaccharides treatment. All these results suggest that spraying Catharanthus roseus leaves with chitooligosaccharides, especially $0.1 \mu \mathrm{g} / \mathrm{mL}$ of $3 \mathrm{kDa}$ chitooligosaccharides, may effectively improve the pharmaceutical value of Catharanthus roseus.
\end{abstract}

Keywords: chitooligosaccharides; Catharanthus roseus; vindoline; catharanthine; antioxidant enzymes activities; gene expression

\section{Introduction}

Catharanthus roseus, a well-known herb with great pharmaceutical value, has been recorded in folklore and traditional medical literature since 50 BC [1]. Catharanthus roseus can be used in the treatments of diabetes, menstrual regulators, hypertension, cancer and antigalactagogue etc. [2]. To date, more than 130 terpenoid indole alkaloids (TIAs), including catharanthine, vindoline, vincristine, vinblastine etc., have been isolated and identified from Catharanthus roseus [3]. Among them, vincristine and vinblastine have been used in antineoplastic drugs and cancer chemotherapies [4]. Furthermore, two precursors of them, catharanthine and vindoline, are also of great significance in the pharmacological functions of Catharanthus roseus. Eltayeb et al. have shown that Catharanthus roseus leaf extract can inhibit the invasive ability of two types of breast cancer cells by regulating 
matrix metalloproteinases activity [5]. According to Mariadi et al., the blood glucose levels in mice reduced quickly after being treated by nanoemulsion of Catharanthus roseus leaf extract [6]. At the same time, Goboza et al. reported that vindoline could lower blood sugar in rats by promoting the action of insulin [7]. In addition, Oguntibeju et al. found that vindoline can reduce diabetes and kidney diseases in rats [8]. However, most TIAs cannot be completely chemically synthesized, and they can only be obtained from plant extract at a very low yield. As a result, many investigations are carried out in order to enhance the production of important TIAs [9].

Since secondary metabolites of plants participate in inducible defense mechanisms, the synthesis of TIAs can be modulated by a variety of elicitors, such as jasmonates, salicylates, and ethylene [10]. Furthermore, it was shown that the content of alkaloids was increased after ultraviolet-B radiation [11]. Artemisinic acid also had incremental effects on the production of vindoline and vinblastine and up-regulated the expression of related genes in the TIAs pathway [12]. As a cell wall-derived elicitor, chitosan can increase the production of plant secondary metabolites [13]. According to Ali et al., chitosan could improve the growth of Catharanthus roseus and increase the accumulation of alkaloids under drought stress [14]. Moreover, it could increase the root weight of Catharanthus roseus and lead to higher alkaloid accumulation by activating the antioxidant defense system and inducing the expression of different genes [15]. However, chitosan is insoluble in water, and it should be dissolved in acetic acid to make chitosan nanoparticles [16]. As the hydrolysate of chitosan, chitooligosaccharides with degrees of polymerization (DP) $<20$ are soluble in water, and recent studies have shown that chitooligosaccharides could regulate plant growth and elicit plant innate immunity, too [17-19]. For example, chitooligosaccharides could significantly enhance the growth and photosynthesis of wheat seedlings [20]. Chitooligosaccharides could exert the strongest improving effect on the synthesis of beneficial secondary metabolites during soybean seeds germination [21,22]. However, according to Zou et al., chitohexaose and chitoheptaosehad had the most efficient effects on alleviating chilling stress to wheat seedlings, which suggested the DP was closely associated with the biological activities of chitooligosaccharides [23]. Thus, we were very interested in exploring whether chitooligosaccharides with different molecular weights could be used as an elicitor in the biosynthesis of TIAs in Catharanthus roseus.

In the present study, the elicitor effect of chitooligosaccharides on Catharanthus roseus was evaluated. The physiological properties, the concentration of vindoline and catharanthine and the antioxidant enzymes activities, as well as genes expression levels of key enzymes in the TIAs synthesis pathway of Catharanthus roseus were detected. To the best of our knowledge, this is the first report on the application of chitooligosaccharides as an inducer in the accumulation of alkaloids in Catharanthus roseus. During the growth period of Catharanthus roseus, foliar spraying with chitooligosaccharides can significantly stimulate the growth of Catharanthus roseus. Most importantly, the vindoline and catharanthine content and antioxidant enzymes activities in the leaves of Catharanthus roseus treated with chitooligosaccharides were considerably higher than that of the control group. In addition, the relative expression of most critical genes in the synthetic pathway of alkaloids increased with chitooligosaccharides treatments.

\section{Results and Discussion}

\subsection{Growth and Morphological Characteristics}

Under changes in external environmental conditions, the most direct manifestation of plants is the changes in their growth and morphological characteristics, in which the fresh weight and height can reflect the growth status of the plant directly [24]. In this experiment, the fresh weights of each part and the height of Catharanthus roseus were measured. According to the results shown in Table 1, the fresh weights of each part of Catharanthus roseus were positively regulated by chitooligosaccharides treatments. They were gradually increased when the concentration of chitooligosaccharides was from 0 to $0.1 \mu \mathrm{g} / \mathrm{mL}$ and decreased when their concentration increased continually. Among them, 
the $3 \mathrm{kDa}$ chitooligosaccharides had the best effect. There was an obvious increase in root weight from $155.56 \mathrm{mg}$ in the control group to $416.26 \mathrm{mg}$ in the treatment of $0.1 \mu \mathrm{g} / \mathrm{mL}$ $3 \mathrm{kDa}$ chitooligosaccharides, about a 2.68-fold increase. The maximum fresh weights of stem and leaf obtained in $0.1 \mu \mathrm{g} / \mathrm{mL} 3 \mathrm{kDa}$ chitooligosaccharides treatment were about 3.40 and 2.36 folds compared with the control group, respectively. At the same condition, the plant height was $6.57 \mathrm{~cm}$, about 1.75-fold compared with the control of $3.75 \mathrm{~cm}$, which could be related to the positive impact of chitooligosaccharides and nutrient uptake due to enhanced root growth.

Table 1. Fresh weights of different parts $(\mathrm{mg})$ and plant height $(\mathrm{cm})$ of Catharanthus roseus under chitooligosaccharides treatments.

\begin{tabular}{cccccc}
\hline Treatment & $\begin{array}{c}\text { COS } \\
\text { Concentration } \\
(\mu \mathrm{g} / \mathbf{m L})\end{array}$ & Root Weight & Stem Weight & Leaf Weight & Plant Height \\
& 0 & $155.56 \pm 51.14 \mathrm{~h}$ & $73.56 \pm 12.58 \mathrm{~h}$ & $297.222 \pm 37.31 \mathrm{~g}$ & $3.75 \pm 0.36 \mathrm{f}$ \\
\hline Control & 0.01 & $199.84 \pm 4.09 \mathrm{fg}$ & $84.58 \pm 3.81 \mathrm{fgh}$ & $375.96 \pm 10.60 \mathrm{f}$ & $4.39 \pm 0.15 \mathrm{de}$ \\
& 0.1 & $293.30 \pm 17.84 \mathrm{c}$ & $102.90 \pm 2.83 \mathrm{f}$ & $434.72 \pm 12.78 \mathrm{e}$ & $4.76 \pm 0.15 \mathrm{~cd}$ \\
$1 \mathrm{kDa} C O S$ & 1 & $187.38 \pm 5.85 \mathrm{fgh}$ & $81.11 \pm 4.60 \mathrm{gh}$ & $366.24 \pm 9.49 \mathrm{f}$ & $4.13 \pm 0.16 \mathrm{ef}$ \\
& 10 & $180.54 \pm 13.19 \mathrm{fgh}$ & $75.68 \pm 1.79 \mathrm{~h}$ & $307.76 \pm 6.12 \mathrm{~g}$ & $3.99 \pm 0.05 \mathrm{ef}$ \\
\hline & 0.01 & $255.19 \pm 6.64 \mathrm{~d}$ & $185.75 \pm 15.70 \mathrm{~d}$ & $475.73 \pm 6.78 \mathrm{~d}$ & $4.58 \pm 0.07 \mathrm{~cd}$ \\
& 0.1 & $333.91 \pm 4.13 \mathrm{~b}$ & $212.13 \pm 12.10 \mathrm{c}$ & $557.72 \pm 16.71 \mathrm{c}$ & $4.95 \pm 0.13 \mathrm{c}$ \\
& 1 & $239.56 \pm 4.00 \mathrm{de}$ & $175.44 \pm 11.53 \mathrm{~d}$ & $409.22 \pm 5.13 \mathrm{e}$ & $4.83 \pm 0.06 \mathrm{~cd}$ \\
& 10 & $214.53 \pm 3.73 \mathrm{ef}$ & $90.64 \pm 6.38 \mathrm{fgh}$ & $318.81 \pm 5.64 \mathrm{~g}$ & $4.41 \pm 0.16 \mathrm{de}$ \\
\hline $\mathrm{kDa}$ COS & 0.01 & $332.00 \pm 12.46 \mathrm{~b}$ & $230.66 \pm 4.79 \mathrm{~b}$ & $621.57 \pm 24.02 \mathrm{~b}$ & $5.49 \pm 0.37 \mathrm{~b}$ \\
& 0.1 & $\mathbf{4 1 6 . 2 6} \pm \mathbf{1 7 . 4 6} \mathbf{a}$ & $\mathbf{2 6 4 . 5 7} \pm \mathbf{1 0 . 5 7} \mathbf{a}$ & $\mathbf{7 0 2 . 3 3} \pm \mathbf{1 3 . 1 0} \mathrm{a}$ & $\mathbf{6 . 5 7} \pm \mathbf{0 . 1 6} \mathbf{a}$ \\
& 1 & $300.46 \pm 19.80 \mathrm{bc}$ & $175.44 \pm 6.80 \mathrm{e}$ & $548.48 \pm 18.34 \mathrm{c}$ & $5.70 \pm 0.19 \mathrm{~b}$ \\
& 10 & $172.40 \pm 5.33 \mathrm{gh}$ & $99.16 \pm 5.20 \mathrm{fg}$ & $355.60 \pm 12.66 \mathrm{f}$ & $4.84 \pm 0.22 \mathrm{~cd}$ \\
\hline
\end{tabular}

COS: chitooligosaccharides. Values represent mean \pm standard deviation $(n=3)$. Values in a column with different letters are significantly different $(p<0.05)$. Best results in bold.

Agrochemicals provide a vast potential to improve plant productivity, but only a few compounds with growth-promoting activity have been described so far [25]. Chitosan and chitooligosaccharides are well documented growth stimulants and are recognized as stress signals by plant cells [26]. However, the DP of chitosan greatly affects the physicochemical properties of plants $[27,28]$. In the present study, chitooligosaccharides had elicitor effects on the root weight, stem weight and leaf weight, as well as plant height of Catharanthus roseus. The results showed that those physiological properties reached the highest values when Catharanthus roseus was treated with $0.1 \mu \mathrm{g} / \mathrm{mL} 3 \mathrm{kDa}$ chitooligosaccharides. These results were in agreement with earlier findings, which showed that chitosan could promote plant growth and development when applied in low quantities. It had been assumed that chitooligosaccharides with different molecular weights might activate different signaling pathways, and they may act as a "metabolic enhancer" to modulate the carbon and nitrogen metabolism in plants [29].

\subsection{Vindoline and Catharanthine Content}

Catharanthus roseus is rich in alkaloids, of which vindoline and catharanthine are the key components in the synthesis of anticancer substances vinblastine and vincristine, and their high yields from the plant facilitate economical bisindole production semisynthetically [30]. As an elicitor, chitooligosaccharides have a low molecular weight and can be recognized as stress signals by plant cells easily [31]. In the present study, the contents of vindoline and catharanthine in the leaves treated with chitooligosaccharides in different molecular weights and concentrations were measured, and the results are shown in Figure 1. The yields of vindoline and catharanthine after chitooligosaccharides treatments increased significantly. The biggest molecular weight led to the highest increase of vindoline under the same treatment concentration (Figure 1A). Vindoline content in- 
creased gradually with the increase of chitooligosaccharides until $0.1 \mu \mathrm{g} / \mathrm{mL}$, and after that, it gradually reduced. With the treatment of $0.1 \mu \mathrm{g} / \mathrm{mL} 3 \mathrm{kDa}$ chitooligosaccharides, the content of vindoline reached $1.88 \mathrm{mg} / \mathrm{g}$ dry weight, which was approximately $60.64 \%$ higher than that of the control. The impact of chitooligosaccharides on catharanthine also showed a similar trend (Figure 1B). The catharanthine content of Catharanthus roseus was increased by $15.17 \%$ with $0.1 \mu \mathrm{g} / \mathrm{mL}$ of $1 \mathrm{kDa}$ chitooligosaccharides treatment. When the molecular weight of chitooligosaccharides increased to $3 \mathrm{kDa}$, catharanthine content reached the maximum, $3.14 \mathrm{mg} / \mathrm{g}$ dry weight, which was approximately $141.78 \%$ higher than that of the control $(1.30 \mathrm{mg} / \mathrm{g}$ dry weight). Increasing the vindoline and catharanthine content due to chitooligosaccharides application may be ascribed to improved growth rate as shown in the former part, and these results were consistent with earlier findings which showed that chitosan could be used as a stimulant in alkaloids accumulation [15,32]. By comparison, chitooligosaccharides have a higher solubility than chitosan, and their use will be more convenient [33].

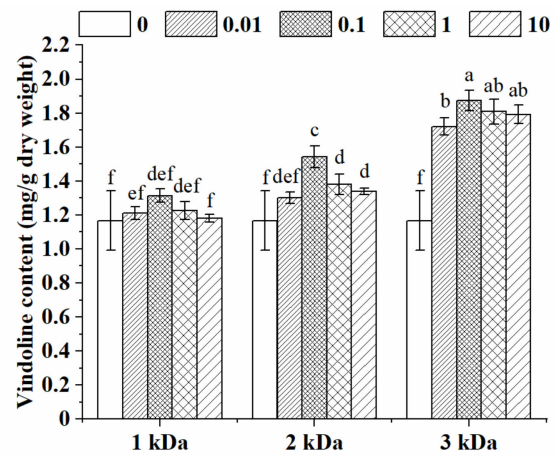

A

Figure 1. Vindoline (A) and catharanthine (B) content in the leaves of Catharanthus roseus under different chitooligosaccharides treatments. The treatments were conducted with chitooligosaccharides of three molecular weights $(1,2$ and $3 \mathrm{kDa})$ at four different concentrations $(0.01,0.1,1$ and $10 \mu \mathrm{g} / \mathrm{mL})$. Vertical bars represent the standard deviation of three replicates. Different letters indicate statistically significant difference at $p<0.05$.

\subsection{Antioxidant Enzymes Activities}

The production of reactive oxygen species in Catharanthus roseus may increase under elicitors treatments, and a series of antioxidant enzymes are produced in order to convert the reactive oxygen species into less toxic substances and reduce oxygen damage to cell membranes, as well as improve the environment for alkaloids biosynthesis $[34,35]$. Therefore, it is vital to study the effects of chitooligosaccharides on the activities of various antioxidant enzymes in Catharanthus roseus.

Catalase can effectively convert excess $\mathrm{H}_{2} \mathrm{O}_{2}$ into water and oxygen [36]. The activity of catalase in the leaves of Catharanthus roseus was determined, and the results are shown in Figure 2A. Except for the $10 \mu \mathrm{g} / \mathrm{mL} 1 \mathrm{kDa}$ group, chitooligosaccharides treatments enhanced the activity of catalase in Catharanthus roseus. With the concentration increase of chitooligosaccharides, catalase activity in leaves increased accordingly. When the concentration reached $0.1 \mu \mathrm{g} / \mathrm{mL}$, catalase activity was increased to the maximum value. However, if the concentration of chitooligosaccharides was increased continually, catalase activity decreased dramatically. In the same concentration, $3 \mathrm{kDa}$ chitooligosaccharides treatments had the highest promoting effects. In treatments with $0.1 \mu \mathrm{g} / \mathrm{mL}$ of $1 \mathrm{kDa}, 2 \mathrm{kDa}$ and $3 \mathrm{kDa}$ chitooligosaccharides, catalase activity in the leaves of Catharanthus roseus was 83.83, 105.02 and $114.36 \mathrm{U} / \mathrm{g}$ fresh weight, respectively. Among them, $3 \mathrm{kDa}$ chitooligosaccharides treatment induced the highest catalase activity, which was $110.15 \%$ higher than that of the control. It has been proved that chitooligosaccharides can improve catalase activity in barley [37]. Accordingly, it was confirmed that the spraying of chitooligosaccharides could improve the catalase activity in Catharanthus roseus. 

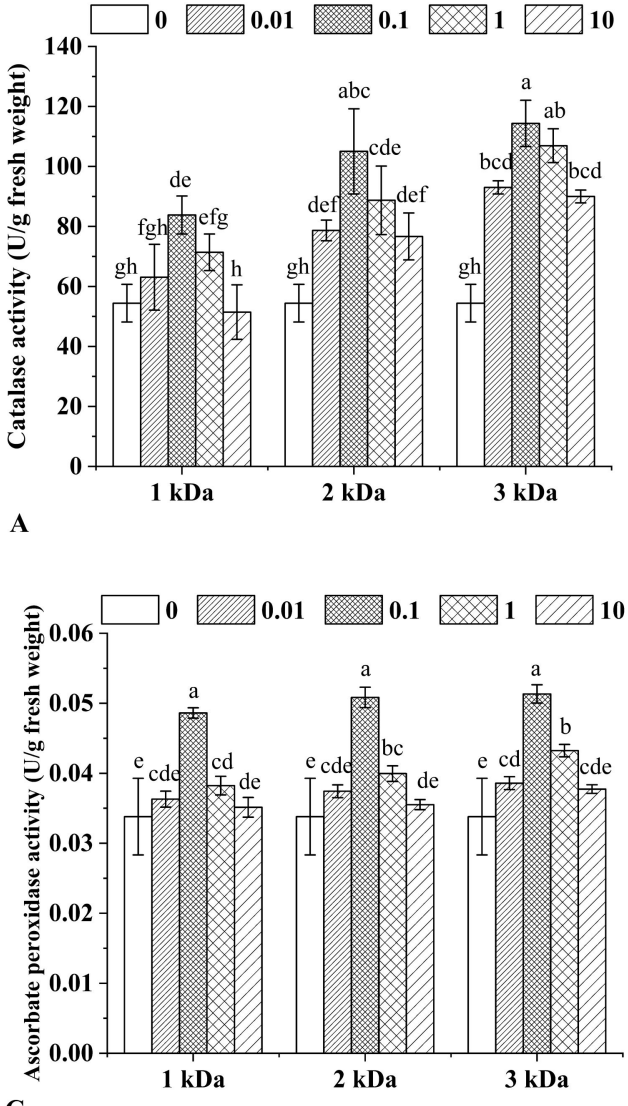
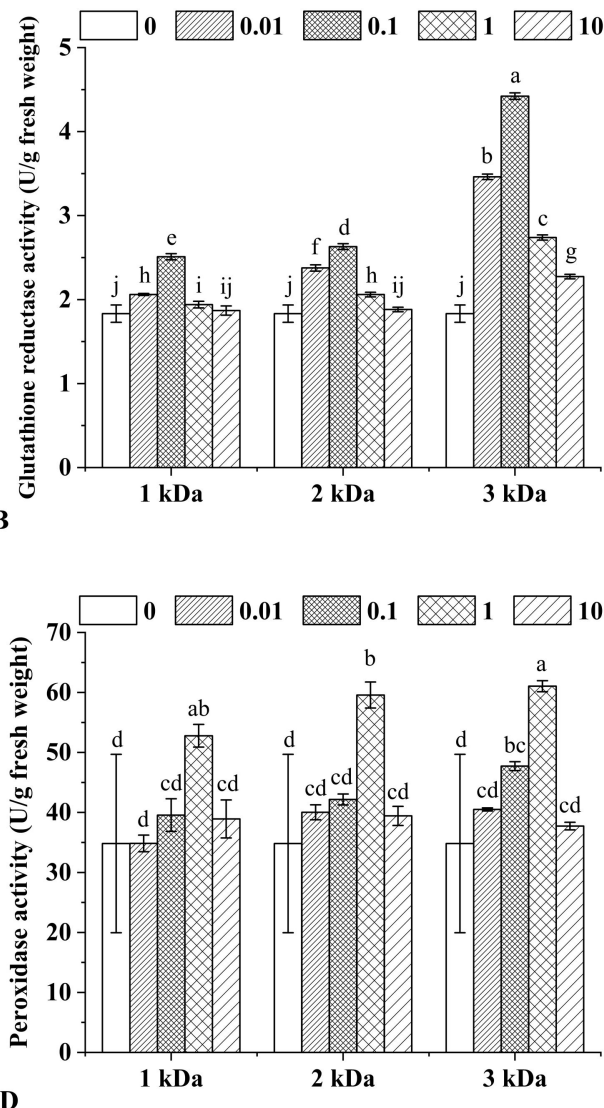

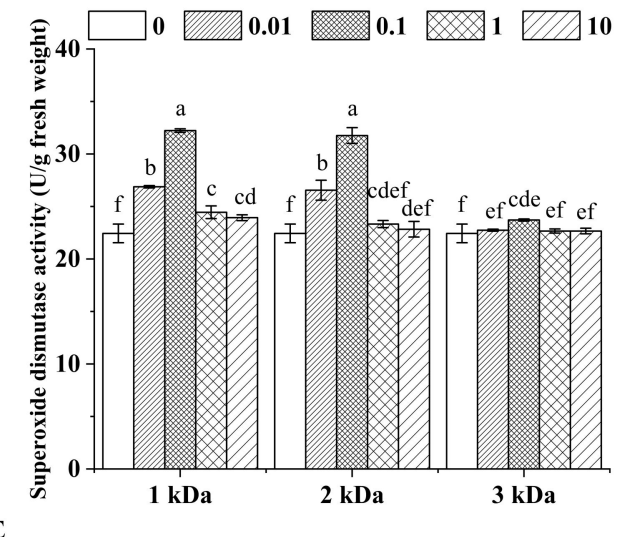

Figure 2. Activities of catalase (A), glutathione reductase (B), ascorbate peroxidase (C), peroxidase (D) and superoxide dismutase (E) in the leaves of Catharanthus roseus under different chitooligosaccharides treatments. The treatments were conducted with chitooligosaccharides of three molecular weights $(1,2$ and $3 \mathrm{kDa})$ at four different concentrations $(0.01,0.1,1$ and $10 \mu \mathrm{g} / \mathrm{mL})$. Vertical bars represent the standard deviation of three replicates. Different letters indicate statistically significant difference at $p<0.05$.

Glutathione reductase is a flavoenzyme that can reduce glutathione (oxidized) (GSSH) to glutathione (reduced) (GSH), and GSH can combine with peroxides and free radicals to prevent the destruction of sulfhydryl groups and protect cells from metalion [38,39]. In the present study, glutathione reductase activity in all chitooligosaccharides treatments was significantly improved (Figure 2B), which coincided with the trend of the catalase activity. Glutathione reductase activity of Catharanthus roseus treated with $0.1 \mu \mathrm{g} / \mathrm{mL}$ of $1 \mathrm{kDa}$ and $2 \mathrm{kDa}$ chitooligosaccharides were 2.51 and $2.63 \mathrm{U} / \mathrm{g}$ fresh weight, which was 
$36.99 \%$ and $46.59 \%$ higher than that of the control. While Catharanthus roseus treated with $0.1 \mu \mathrm{g} / \mathrm{mL}$ of $3 \mathrm{kDa}$ chitooligosaccharides had the highest glutathione reductase activity, which was $4.42 \mathrm{U} / \mathrm{g}$ fresh weight, representing a $141.38 \%$ increase. These results were compliant with the report of Misra et al., who clarified that saline and nitrogen sources could cause an increase of glutathione reductase and total alkaloid accumulation in the leaves of Catharanthus roseus [40].

Ascorbate peroxidase is an important enzyme that catalyzes $\mathrm{H}_{2} \mathrm{O}_{2}$-dependent ascorbate oxidation through a peroxidative one-electron transfer mechanism [41]. In the current study, Catharanthus roseus treated with chitooligosaccharides depicted higher activity of ascorbate peroxidase than the control (Figure 2C). Regardless of the molecular weight, ascorbate peroxidase activity first increased and then decreased with the concentration increase of chitooligosaccharides, and the best concentration was $0.1 \mu \mathrm{g} / \mathrm{mL}$. The highest ascorbate peroxidase activity was $0.051 \mathrm{U} / \mathrm{g}$ fresh weight when treated by $0.1 \mu \mathrm{g} / \mathrm{mL}$, $3 \mathrm{kDa}$ chitooligosaccharides, increasing by $51.84 \%$ compared with the control group. These results were similar to the increase in ascorbate peroxidase activity as a result of jasmonic acid treatments [3].

Peroxidase decomposes $\mathrm{H}_{2} \mathrm{O}_{2}$ to produce phenolic polymers, thereby enhancing the strength of the cell wall and inhibiting the entry of heavy metals [42,43]. In the present study, the activity of peroxidase was measured to further verify the promotion effects of chitooligosaccharides on the antioxidant defense system in Catharanthus roseus leaves. As shown in Figure 2D, regardless of molecular weight, after chitooligosaccharides treatments, the peroxidase activity of Catharanthus roseus was significantly increased. When the concentration of chitooligosaccharides increased from 0 to $1 \mu \mathrm{g} / \mathrm{mL}$, the activity of peroxidase gradually increased, while from 1 to $10 \mu \mathrm{g} / \mathrm{mL}$, its activity decreased significantly. The peroxidase activity of Catharanthus roseus leaves treated with $1 \mu \mathrm{g} / \mathrm{mL} 3 \mathrm{kDa}$ chitooligosaccharides showed the highest increase, reaching $75.33 \%$ more than the control. The increases of catalase and peroxidase in this experiment were similar to the result of a combination treatment with sodium nitroprusside and melatonin [44]. However, sodium nitroprusside is harmful to the environment and can cause pollution to water bodies, soil and the atmosphere. In contrast, chitooligosaccharides are more environmentally friendly and more suitable as a stimulant.

Superoxide dismutase is a front-line antioxidant enzyme catalyzing superoxide breakdown, and it is essential for most forms of eukaryotic life [45]. The effects of chitooligosaccharides on superoxide dismutase activity in Catharanthus roseus are illustrated in Figure 2E. For the three molecular weights, with the increased concentration of chitooligosaccharides, the activity of superoxide dismutase in Catharanthus roseus leaves increased, and when it was $0.1 \mu \mathrm{g} / \mathrm{mL}$, it reached the maximum value. Among them, superoxide dismutase activity in Catharanthus roseus leaves treated with $1 \mathrm{kDa}$ chitooligosaccharides was $43.66 \%$ higher than the control. The results of superoxide dismutase resembled the increase as a result of methyl jasmonate and putrescine treatments [46].

Studies have shown that oxidative stress may be important in stimulating alkaloids biosynthesis [3]. In this regard, oxidative stress occurs in treatments of chitooligosaccharides, and plants alleviated oxidative stress via increasing antioxidant enzymes activities to scavenge reactive oxygen species. The impact of chitooligosaccharides on antioxidant enzymes activities we observed was in accordance with a previous study, which reported chitooligosaccharides to have positive effects on elicitation of plant defense reactions [47]. Furthermore, it is reported that alkaloids accumulation was significantly correlated with antioxidant enzymes activities [3]. The results of this study showed that the content of vindoline and catharanthine, as well as antioxidant enzymes activities, increased as a defense response.

\subsection{Expression Determination of Key Enzymatic Genes}

Due to the complicated chemical structure of most TIAs, they can only be produced in Catharanthus roseus at a very low quantity [48]. In order to effectively increase the production 
of alkaloids in this unique plant source, the pathways of TIAs, especially the critical enzymes in the biosynthesis of alkaloids, as well as the metabolic regulation mechanism of alkaloids in Catharanthus roseus, have been studied in detail [49]. It is revealed that more than 35 available intermediates and 30 enzymatic steps are involved in the synthesis of Catharanthus roseus TIAs [50]. Overall, the secondary metabolic synthesis of alkaloids can be divided into upstream, midstream and downstream stages. In the upstream synthesis stage, strictosidine is synthesized by the coupling of tryptamine and secologanin, which are supplied by the shikimate pathway and the methylerythritol pathway/iridoid pathway, respectively. In the midstream synthesis stage, catharanthine and tabersonine are generated through a multi-step enzymatic reaction with strictosidine as the common precursor. In the downstream stage, vindoline is derived from tabersonine, and vinblastine and vincristine are synthesized by the condensation of catharanthine and vindoline [51]. These processes involve multi-step enzymatic reactions. For example, SLS and STR are engaged in the upstream stage, and SLS can catalyze the conversion of loganin to secologanin. Then, secologanin is combined with tryptamine to form strictosidine under the catalysis of STR. SGD can catalyze the removal of the glucose moiety from strictosidine to form the aglycone, which is converted to reactive dialdehyde as a precursor for the biosynthesis of TIAs. T16H, $\mathrm{D} 4 \mathrm{H}$ and DAT are three critical enzymes in the pathways from tabersonine to vindoline, and DAT can convert deacetylvindoline to vindoline. In the downstream stage, PRX1 catalyzes the dimerisation of vindoline and catharanthine to product $\alpha-3^{\prime}, 4^{\prime}$ anhydrovinblastine, and then vinblastine is produced in the next step. At the same time, transcriptional regulation of metabolic pathways is controlled by many transcriptional factors, and ORCA3 has been reported to participate in the regulation of secondary metabolism, and its overexpression can activate the expression of genes such as SLS, STR and SGD, etc. [52].

In order to explore the effects of chitooligosaccharides on the synthesis of TIAs at the genetic level, qRT-PCR was used to detect the expression of the genes in the synthesis pathway of vindoline and catharanthine. As shown in Figure 3, the expressions of the SLS, STR, SGD , T16H, D4H, DAT, PRX1 and ORCA3 were all up-regulated with chitooligosaccharides treatments. Among them, the transcription levels of SLS, STR, DAT, PRX1 and $O R C A 3$ significantly increased with the increase of chitooligosaccharides concentration until $0.1 \mu \mathrm{g} / \mathrm{mL}$, and after that, they gradually reduced. For these five genes, the biggest molecular weight led to the highest increase of them under the same treatment concentration. Among them, the transcript abundance of SLS, STR, DAT and PRX1 increased by 15.22-fold, 5.61-fold, 6.57-fold and 4.29-fold, respectively. Therefore, chitooligosaccharides might trigger the intrinsic genetic potential by promoting the transcriptional activation of key genes SLS, STR, DAT and PRX1. These results were consistent with earlier research. For example, sucrose has a positive effect on expression levels of STR, DAT and PRX1, as well as the production of alkaloids by activating the defense responses of plants [53]. According to Pandey et al., vindoline biosynthesis is induced by selected endophytes as a result of up-regulation of TIAs biosynthesis-related genes, including STR, D4H, DAT and ORCA3 [54]. In the group of $0.1 \mu \mathrm{g} / \mathrm{mL} 3 \mathrm{kDa}$ chitooligosaccharides treatment, the transcription abundance of $O R C A 3$ reached its maximal level, about 9.71 folds compared to the control. According to earlier research, ORCA3 plays an important role in regulating TIAs pathway genes, and its overexpression will activate the accumulation of alkaloids [53]. While after treating Catharanthus roseus with 1,2 and $3 \mathrm{kDa}$ chitooligosaccharides at the same concentration, the expression of $S G D$ and $T 16 \mathrm{H}$ decreased with the increase of molecular weight.

The improvement effects reached the maximum when the molecular weight was $1 \mathrm{kDa}$, and the optimal treatment concentration was $0.1 \mu \mathrm{g} / \mathrm{mL}$. The $D 4 H$ transcription level slowly increased from 0 to $1 \mu \mathrm{g} / \mathrm{mL}$ of chitooligosaccharides treatments, and the highest level of transcription was observed at $1 \mu \mathrm{g} / \mathrm{mL} 3 \mathrm{kDa}$ chitooligosaccharides treatment. This is similar to an earlier report, which found that the increase of vindoline coincides with the increase in $\mathrm{T16H}$ and $\mathrm{D} 4 \mathrm{H}$ transcript levels after the elicitation effect of artemisinic acid [12]. In addition, the up-regulated expression of $S G D, D 4 H$ and $T 16 H$ are contributed 
to the increased contents of vindoline and catharanthine under binary stress of UV-B irradiation and dark incubation [55]. However, the expression of these three genes did not correlate with the change in vindoline and catharanthine accumulation in response to chitooligosaccharides treatments, suggesting that there are posttranscriptional and posttranslational mechanisms, as well as other complex regulatory mechanisms involved in a spatial and temporal manner [56]. Generally, chitooligosaccharides could stimulate the expression of the eight key genes on vindoline and catharanthine biosynthesis in the TIAs biosynthetic pathway, finally leading to the accumulation of TIAs.
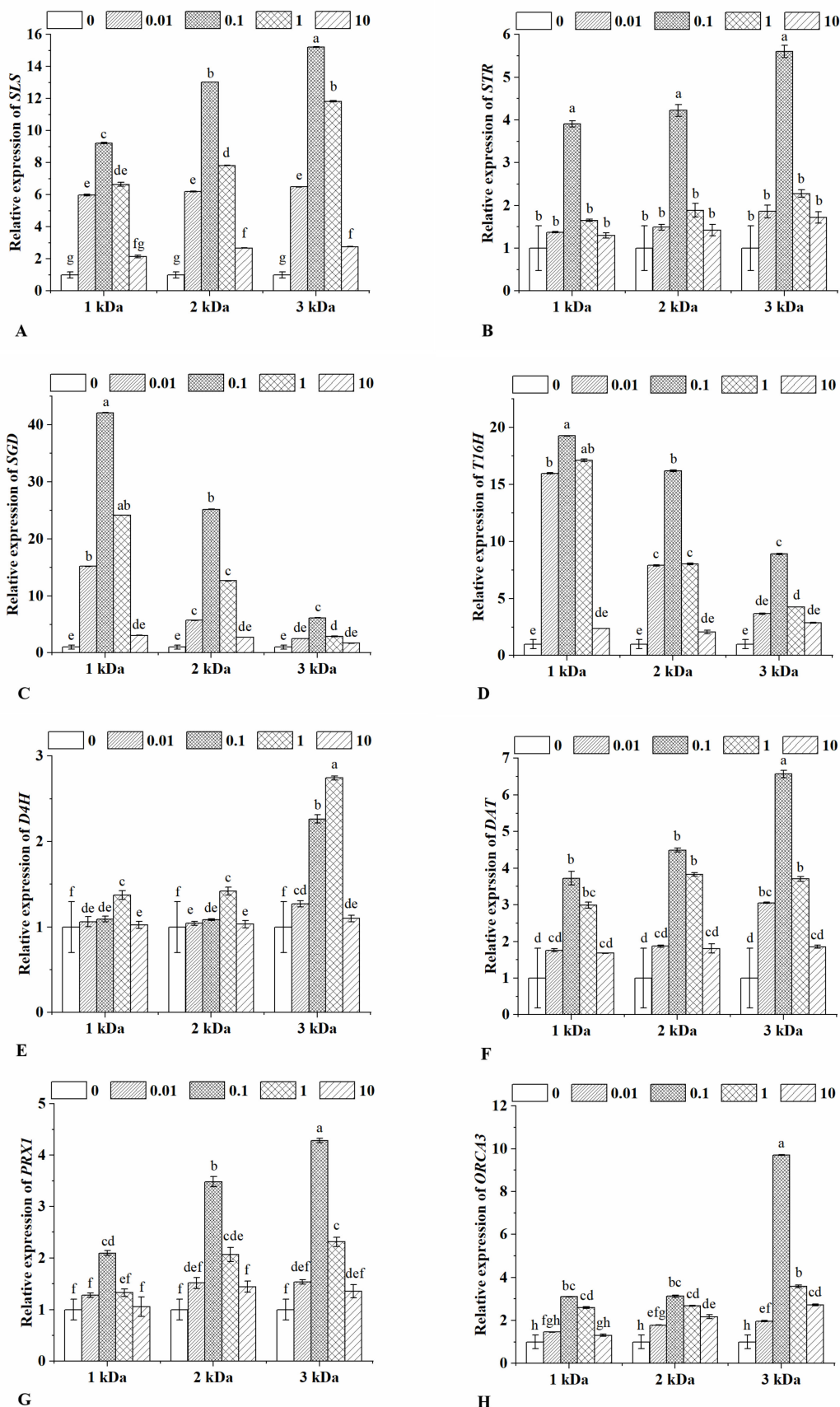

Figure 3. Relative expression of $S L S$ (A), STR (B), SGD (C), T16H (D), D4H (E), DAT (F), PRX1 (G) and $O R C A 3(\mathbf{H})$ in the leaves of Catharanthus roseus under different chitooligosaccharides treatments. The treatments were conducted with chitooligosaccharides of three molecular weights $(1,2$ and $3 \mathrm{kDa})$ at four different concentrations $(0.01,0.1,1$ and $10 \mu \mathrm{g} / \mathrm{mL})$. Vertical bars represent the standard deviation of three replicates. Different letters indicate statistically significant difference at $p<0.05$. 


\section{Materials and Methods}

\subsection{Plant Material, Chitooligosaccharides and Chemicals}

Catharanthus roseus seeds were preserved by the School of Biological Engineering, Dalian Polytechnic University. The soil was purchased from Shenzhibei Agricultural Technology Co., Ltd. (Baishan, China). Chitooligosaccharides with different molecular weights (1, 2 and $3 \mathrm{kDa}$ ) were purchased from Golden Shell Pharmaceutical Co., Ltd. (Zhejiang, China), and according to the website of the company, chitooligosaccharides products with different average molecular weights and low dispersion degrees are prepared by strictly controlled chitosan hydrolysis using specific GS chitosanase as well as membrane separation technology [57]. Vindoline and catharanthine were purchased from Yuanye Biological Technology Co., Ltd. (Shanghai, China). Methanol was purchased from Merck and Co., Inc. (Burlington, VT, USA). RNAiso Plus, PrimeScriptTM RT reagent Kit with gDNA Eraser (Perfect Real Time), TB Green Premix EX Taq II were purchased from Takara Bio Inc. (Dalian, China).

\subsection{Treatments of Catharanthus Roseus with Chitooligosaccharides}

Catharanthus roseus seeds were soaked in water and cultured in a constant temperature incubator (Jinghong, H-1204107, Shanghai, China). After the buds were exposed, they were transferred to the soil and cultured in a greenhouse at $25^{\circ} \mathrm{C}$ with a $16 \mathrm{~h}$ light $/ 8 \mathrm{~h}$ non-light cycle. There were $1 \mathrm{~mL}$ of $0.01 \mu \mathrm{g} / \mathrm{mL}, 0.1 \mu \mathrm{g} / \mathrm{mL}, 1 \mu \mathrm{g} / \mathrm{mL}$ and $10 \mu \mathrm{g} / \mathrm{mL}$ of chitooligosaccharides with different molecular weights $1 \mathrm{kDa}, 2 \mathrm{kDa}$ and $3 \mathrm{kDa}$ were sprayed to the leaves at a frequency of every five days. For the control treatment, water was used instead of chitooligosaccharides. After twenty days' treatment, three pairs of new leaves appeared, and the seedlings were collected for the next experiments.

\subsection{Determination of the Physiological Properties}

The plant height and fresh weights of root, stem and leaf of Catharanthus roseus were measured according to Pérez-Harguindeguy's methods [58].

\subsection{HPLC Analysis of Vindoline and Catharanthine Content}

After harvest, the leaves in the seedlings were freeze-dried and ground into powder (Jiuyang, modelJYL-C16V, Jinan, China). Then, $100 \mathrm{mg}$ of the powder was extracted with $1 \mathrm{~mL}$ of $95 \%$ methanol for $60 \mathrm{~min}$ at room temperature and centrifuged at 10,000 rpm for $15 \mathrm{~min}$. The supernatant was collected and used for the vindoline and catharanthine content determination.

The content of vindoline and catharanthine was determined by HPLC with a Poroshell 120 EC-C18 column ( $4.6 \times 250$ mm, $4 \mu \mathrm{m}$ particle size) (Waldbronn, Germany). The mobile phase consisted of water (A) and methanol (B). The flow rate was $1 \mathrm{~mL} / \mathrm{min}$, the column temperature was $30^{\circ} \mathrm{C}$, and the injection volume was $10 \mu \mathrm{L}$. The gradient elution process began with the mobile phase A at $80 \%$ in the first $20 \mathrm{~min}$, then decreased from $80 \%$ to $20 \%$ for the next $10 \mathrm{~min}$, while in the following $10 \mathrm{~min}$ it increased from $20 \%$ to $80 \%$, and maintained at $80 \%$ in the last $10 \mathrm{~min}$. The detection wavelengths were $310 \mathrm{~nm}$ and $280 \mathrm{~nm}$ for vindoline and catharanthine, respectively. The concentrations of vindoline and catharanthine in the sample were calculated from standard curves of each, and they were expressed as milligram per gram of dry weight.

\subsection{Assays of Antioxidant Enzymes Activities}

A crude enzyme extract was prepared by homogenizing $500 \mathrm{mg}$ of leaves in $10 \mathrm{~mL}$ phosphate buffer $(50 \mathrm{mM}, \mathrm{pH} 7.8)$ at $4^{\circ} \mathrm{C}$. The homogenates were centrifuged at 10,000 rpm for $30 \mathrm{~min}$, and the supernatant was used for antioxidant enzymes activities assay.

Catalase was measured by determining the decomposition of $\mathrm{H}_{2} \mathrm{O}_{2}$ at $240 \mathrm{~nm}$ using a spectrophotometer (Molecular Devices, model SpectraMax Plus 384, San Jose, CA, USA) and ascorbate peroxidase activity was determined according to the oxidation rate of ascorbic acid at $290 \mathrm{~nm}$ [59]. Peroxidase activity was determined by monitoring the increase in the 
absorbance of $425 \mathrm{~nm}$ due to the oxidation of guaiacol, and superoxide dismutase was detected by following the inhibition of nitroblue tetrazolium reduction at $560 \mathrm{~nm}$ [59]. The activity of glutathione reductase was measured according to the increase at $412 \mathrm{~nm}$ due to the formation of 2-nitro-5-thiobenzoic acid [40].

\subsection{Gene Expression Profiling and Analysis}

3.6.1. Primers

The genes coding the key enzymes in TIAs synthesis, as well as the reference gene, $40 S$ ribosomal protein S9 (RSP9), were downloaded from the GenBank database [60], and the primers used in qRT-PCR are listed in Table 2.

Table 2. Primers used for the qRT-PCR analysis.

\begin{tabular}{cc}
\hline Primer $\mathbf{N a m e}$ & Sequence $\mathbf{( 5}^{\prime} \rightarrow \mathbf{3}^{\prime} \mathbf{)}$ \\
\hline$S L S-F$ & GTTCCTTCTCACCGGAGTTG \\
$S L S-R$ & CCCATTTGGTCAACATGTCA \\
$S T R-F$ & AAAATTCCCGATACTCCG \\
$S T R-R$ & ACCAATGGGCACTTCCTT \\
$S G D-F$ & TCACAAAGCTGCTGTGGAAG \\
$S G D-R$ & CACCCGTTGTTAATGGCTCT \\
$T 16 H-F$ & AGGACCTTGTTGATGTGCTAC \\
$T 16 H-R$ & CATTGCCCAATCGACTGTTG \\
$D 4 H-F$ & TACCCTGCATGCCCTCAACC \\
$D 4 H-R$ & TTGAAGGCCGCCAATTGAT \\
$D A T-F$ & AAACCCTCTTCTCCAACCCCTC \\
$D A T-R$ & CTTCCACGAACTCAATTCCATC \\
$P R X 1-F$ & CTGCTGCTTCTTCTCATTTCC \\
$P R X 1-R$ & CAACATCGTTTTGGAAGACCT \\
$O R C A 3-F$ & CGAATTCAATGGCGGAAAGC \\
$O R C A 3-R$ & CCTTATCTCCGCCGCGAACT \\
$R S P 9-F$ & GAGGGCCAAAACAAACTTGA \\
$R S P 9-R$ & CCCTTATGTGCCTTTGCCTA \\
\hline
\end{tabular}

\subsubsection{RNA Extraction and cDNA Synthesis}

The leaves in the seedlings of Catharanthus roseus were collected and frozen in liquid nitrogen. RNAiso Plus was used to extract total RNA from the samples. The template strand cDNA was synthesized from total RNA following the instructions of PrimeScriptTM RT reagent Kit with gDNA Eraser (Perfect Real Time).

\subsection{3. qRT-PCR Analysis}

qRT-PCR analysis was carried out for 8 TIAs biosynthesis-related genes (SLS, STR, $S G D, T 16 H, D 4 H, D A T, P R X 1$ and ORCA3). Each $25 \mu \mathrm{L}$ reaction mixture was comprised of $2 \mu \mathrm{L} \mathrm{cDNA}(35 \mathrm{ng} / \mu \mathrm{L}), 1 \mu \mathrm{L}$ each of PCR forward primer $(10 \mu \mathrm{M})$ and PCR reverse primer $(10 \mu \mathrm{M})$, and $12.5 \mu \mathrm{L}$ TB Green Premix EX Taq II $(2 \times)$ and $8.5 \mu \mathrm{L}$ sterilized water. The PCR condition was set as $95^{\circ} \mathrm{C}$ for $30 \mathrm{~s}, 40$ cycles of $95^{\circ} \mathrm{C}$ for $15 \mathrm{~s}$ and $50{ }^{\circ} \mathrm{C}$ for $20 \mathrm{~s}$, and $72{ }^{\circ} \mathrm{C}$ for $15 \mathrm{~s}$. The reference gene $R S P 9$ was used as an internal control, and the $2^{-\Delta \Delta \mathrm{Ct}}$ method was used in relative quantification of the genes' expression level [61].

\subsection{Statistical Analysis}

All tests were analyzed with at least three replicates, and data were calculated as the mean \pm standard deviation. Statistical analysis was performed using SPSS software (SPSS, Chicago, IL, USA). Duncan's multiple range test was used to compare the means at $p<0.05$.

\section{Conclusions}

Chitooligosaccharides could significantly improve the physiological properties, alkaloids content and antioxidant properties of Catharanthus roseus. The root weight, stem 
weight, leaf weight and plant height of Catharanthus roseus were markedly promoted by chitooligosaccharides treatments. At the same time, the accumulation of vindoline and catharanthine was significantly increased with $0.1 \mu \mathrm{g} / \mathrm{mL} 3 \mathrm{kDa}$ chitooligosaccharides treatment. Chitooligosaccharides can also improve the activities of catalase, glutathione reductase, ascorbate peroxidase, peroxidase and superoxide dismutase in Catharanthus roseus leaves. In addition, chitooligosaccharides mightily boosted the expression of key enzymatic genes such as SLS, STR, SGD, T16H,D4H,DAT, PRX1 and a transcriptional regulator gene ORCA3 in the TIAs synthesis pathway. As a result, foliar application of chitooligosaccharides could improve the accumulation of vindoline and catharanthine in Catharanthus roseus leaves by activating the defense responses and up-regulating the transcriptions of key genes, so chitooligosaccharides could be used as a promising abiotic elicitor for the production of TIAs.

Author Contributions: Conceptualization, W.T. and F.Y.; methodology, W.T. and X.L.; validation, W.T., X.L. and Y.H.; formal analysis, Y.H.; investigation, X.L. and Y.H.; resources, W.T. and F.Y.; data curation, W.T. and F.Y.; writing-original draft preparation, W.T., X.L. and Y.H.; writing-review and editing, W.T. and F.Y.; visualization, W.T., X.L. and Y.H.; supervision, F.Y.; project administration, W.T. and F.Y.; funding acquisition, W.T. and F.Y. All authors have read and agreed to the published version of the manuscript.

Funding: This study was supported by Basic Research Projects of Liaoning Higher Education Institutions (2017J030) and the Dalian High-level Talent Innovation Support Program (2018RQ24).

Institutional Review Board Statement: Not applicable.

Informed Consent Statement: Not applicable.

Data Availability Statement: Data is contained within the article.

Conflicts of Interest: No potential conflict of interest was reported by the authors.

\section{References}

1. Kulkarni, R.N.; Baskaran, K.; Jhang, T. Breeding medicinal plant, periwinkle Catharanthus roseus (L.) G. Don: A review. Plant Genet. Resour. 2016, 14, 283-302. [CrossRef]

2. Aslam, J.; Khan, S.H.; Siddiqui, Z.H.; Fatima, Z.; Maqsood, M.; Bhat, M.A.; Nasim, S.A.; Ilah, A.; Ahmad, I.Z.; Khan, S.A.; et al. Catharanthus roseus (L.) G. Don. an important drug: Its applications and production. Pharm. Glob. 2010, 4, 1-16.

3. Ababaf, M.; Omidi, H.; Bakhshandeh, A. Changes in antioxidant enzymes activities and alkaloid amount of Catharanthus roseus in response to plant growth regulators under drought condition. Ind. Crops Prod. 2021, 167, 113505. [CrossRef]

4. Madsen, M.L.; Due, H.; Ejskjær, N.; Jensen, P.; Madsen, J.; Dybkær, K. Aspects of vincristine-induced neuropathy in hematologic malignancies: A systematic review. Cancer Chemother. Pharmacol. 2019, 84, 471-485. [CrossRef] [PubMed]

5. Eltayeb, N.M.; Ng, S.Y.; Ismail, Z.; Salhimi, S.M. Anti-invasive effect of Catharanthus roseus extract on highly metastatic human breast cancer MDA-MB-231 cells. J. Teknol. 2016, 78, 35-40. [CrossRef]

6. Mariadi; Prasetyo, B.E.; Adela, H.; Wiladatika, W. Formulation and characterization of nanoemulsion of tread leave ethanol extract (Catharanthus roseus (L.) G. Don) as antihyperglycemic. Indones. J. Pharm. Clin. Res. 2019, 2, 24-30. [CrossRef]

7. Goboza, M.; Aboua, Y.G.; Chengou, N.; Oguntibeju, O.O. Vindoline effectively ameliorated diabetes-induced hepatotoxicity by docking oxidative stress, inflammation and hypertriglyceridemia in type 2 diabetes-induced male Wistar rats. Biomed. Pharmacother. 2019, 112, 108638. [CrossRef]

8. Oguntibeju, O.O.; Aboua, Y.; Goboza, M. Vindoline-a natural product from Catharanthus roseus reduces hyperlipidemia and renal pathophysiology in experimental type 2 diabetes. Biomedicines 2019, 7, 59. [CrossRef]

9. Wang, Y.Y.; Yang, B.R.; Zhang, M.X.; Jia, S.S.; Yu, F. Application of transport engineering to promote catharanthine production in Catharanthus roseus hairy roots. Plant Cell Tissue Organ Cult. 2019, 139, 523-530. [CrossRef]

10. Vázquez-Flota, F.; Hernández-Domínguez, E.; Ma, M.H.; Monforte-González, M. A differential response to chemical elicitors in Catharanthus roseus in vitro cultures. Biotechnol. lett. 2009, 31, 591-595. [CrossRef]

11. Zhong, Z.H.; Liu, S.Z.; Han, S.L.; Li, Y.H.; Tao, M.L.; Liu, A.M.; He, Q.; Chen, S.X.; Dufresne, C.; Zhu, W.; et al. Integrative omic analysis reveals the improvement of alkaloid accumulation by ultraviolet-B radiation and its upstream regulation in Catharanthus roseus. Ind. Crops Prod. 2021, 166, 113448. [CrossRef]

12. Liu, J.W.; Zhu, J.H.; Tang, L.; Wen, W.; Lv, S.S.; Yu, R.M. Enhancement of vindoline and vinblastine production in suspensioncultured cells of Catharanthus roseus by artemisinic acid elicitation. World J. Microbiol. Biotechol. 2014, 30, 175-180. [CrossRef]

13. Karla, R.E.; Heriberto, V.L.; Diego, H.; Elisabeth, M.; Marta, G.; Rosa, C.; Javier, P. Elicitation, an effective strategy for the biotechnological production of bioactive high-added value compounds in plant cell factories. Molecules 2016, $21,182$. 
14. Ali, E.F.; El-Shehawi, A.M.; Ibrahim, O.H.M.; Abdul-Hafeez, E.Y.; Moussa, M.M.; Hassan, F.A.S. A vital role of chitosan nanoparticles in improvisation the drought stress tolerance in Catharanthus roseus (L.) through biochemical and gene expression modulation. Plant Physiol. Biochem. 2021, 161, 166-175. [CrossRef]

15. Hassan, F.A.S.; Ali, E.; Gaber, A.; Fetouh, M.I.; Mazrou, R. Chitosan nanoparticles effectively combat salinity stress by enhancing antioxidant activity and alkaloid biosynthesis in Catharanthus roseus (L.) G. Don. Plant Physiol. Biochem. 2021, 162, 291-300. [CrossRef]

16. Wang, W.Q.; Meng, Q.Y.; Li, Q.; Liu, J.B.; Zhou, M.; Jin, Z.; Zhao, K. Chitosan derivatives and their application in biomedicine. Int. J. Mol. Sci. 2020, 21, 487. [CrossRef]

17. Mourya, V.K.; Inamdar, N.N.; Choudhari, Y.M. Chitooligosaccharides: Synthesis, characterization and applications. Polym. Sci. 2011, 53, 583-612. [CrossRef]

18. Li, Y.Q.; Kong, D.X.; Fu, Y.; Sussman, M.R.; Wu, H. The effect of developmental and environmental factors on secondary metabolites in medicinal plants. Plant Physiol. Biochem. 2020, 148, 80-89. [CrossRef]

19. Kumar, M.; Rajput, M.; Soni, T.; Vivekanand, V.; Pareek, N. Chemoenzymatic production and engineering of chitooligosaccharides and N-acetyl glucosamine for refining biological activities. Front. Chem. 2020, 8, 469. [CrossRef]

20. Zhang, X.Q.; Li, K.C.; Liu, S.; Xing, R.E.; Yu, H.H.; Chen, X.L.; Li, P.C. Size effects of chitooligomers on the growth and photosynthetic characteristics of wheat seedlings. Carbohydr. Polym. 2016, 138, 27-33. [CrossRef]

21. Jia, Y.J.; Ma, Y.L.; Zou, P.; Cheng, G.G.; Zhou, J.X.; Cai, S.B. Effects of different oligochitosans on isoflavone metabolites, antioxidant activity and isoflavone biosynthetic genes in soybean (Glycine max) seeds during germination. J. Agric. Food Chem. 2019, 67, 4652-4661. [CrossRef]

22. Tang, W.Z.; Lei, X.T.; Liu, X.Q.; Yang, F. Nutritional improvement of bean sprouts by using chitooligosaccharide as an elicitor in germination of soybean (Glycine max L.). Appl. Sci. 2021, 11, 7695. [CrossRef]

23. Zou, P.; Tian, X.Y.; Dong, B.; Zhang, C.S. Size effects of chitooligomers with certain degrees of polymerization on the chilling tolerance of wheat seedlings. Carbohydr. Polym. 2017, 160, 194-202. [CrossRef]

24. Smith, S.E.; Smith, F.A. Fresh perspectives on the roles of arbuscular mycorrhizal fungi in plant nutrition and growth. Mycologia 2012, 104, 1-13. [CrossRef] [PubMed]

25. Steenackers, W.; Houari, I.E.; Baekelandt, A.; Witvrouw, K.; Dhondt, S.; Leroux, O.; Gonzalez, N.; Corneillie, S.; Cesarino, I.; Inze, D.; et al. cis-Cinnamic acid is a natural plant growth-promoting compound. J. Exp. Bot. 2019, 70, 6293-6304. [CrossRef] [PubMed]

26. Tabassum, N.; Ahmed, S.; Ali, M.A. Chitooligosaccharides and their structural-functional effect on hydrogels: A review. Carbohydr. Polym. 2021, 261, 117882. [CrossRef]

27. Gonçalves, C.; Ferreira, N.; Lourenço, L. Production of low molecular weight chitosan and chitooligosaccharides (COS): A review. Polymers 2021, 13, 2466. [CrossRef] [PubMed]

28. Yin, H.; Du, Y.G.; Dong, Z.M. Chitin oligosaccharide and chitosan oligosaccharide: Two similar but different plant elicitors. Front Plant Sci. 2016, 7, 522. [CrossRef]

29. Li, K.C.; Xing, R.E.; Liu, S.; Li, P.C. Chitin and chitosan fragments responsible for plant elicitor and growth stimulator. J. Agric. Food Chem. 2020, 68, 12203-12211. [CrossRef]

30. Mall, M.; Verma, R.K.; Gupta, M.M.; Shasany, A.K.; Khanuja, S.P.S.; Shukla, A.K. Influence of seasonal and ontogenic parameters on the pattern of key terpenoid indole alkaloids biosynthesized in the leaves of Catharanthus roseus. S. Afr. J. Bot. 2019, 123, 98-104. [CrossRef]

31. Mukarram, M.; Naeem, M.; Aftab, T.; Khan, M.M.A. Radiation-Processed Polysaccharides: Emerging Roles in Agriculture: Chitin, Chitosan, and Chitooligosaccharides: Recent Advances and Future Perspectives; Naeem, M., Aftab, T., Khan, M.M.A., Eds.; Academic Press: New York, NY, USA, 2021; pp. 339-353.

32. Pliankong, P.; Suksa-Ard, P.; Wannakrairoj, S. Chitosan elicitation for enhancing of vincristine and vinblastine accumulation in cell culture of Catharanthus roseus (L.) G. Don. J. Agric. Sci. 2018, 10, 287. [CrossRef]

33. Mengibar, M.; Mateos-Aparicio, I.; Miralles, B.; Heras, A. Influence of the physico-chemical characteristics of chitooligosaccharides (COS) on antioxidant activity. Carbohydr. Polym. 2013, 97, 776-782. [CrossRef]

34. Dhayanithy, G.; Subban, K.; Chelliah, J. Diversity and biological activities of endophytic fungi associated with Catharanthus roseus. BMC Microbiol. 2019, 19, 22. [CrossRef]

35. Ochoa-Meza, L.C.; Quintana-Obregón, E.A.; Vargas-Arispuro, I.; Falcón-Rodríguez, A.B.; Aispuro-Hernández, E.; Virgen-Ortiz, J.J.; Martínez-Téllez, M.Á. Oligosaccharins as elicitors of defense responses in wheat. Polymers 2021, 13, 3105. [CrossRef]

36. Sepasi Tehrani, H.; Moosavi-Movahedi, A.A. Catalase and its mysteries. Prog. Biophys. Mol. Biol. 2018, 140, 5-12. [CrossRef]

37. Lan, W.Q.; Wang, W.; Yu, Z.M.; Qin, Y.X.; Luan, J.; Li, X.Z. Enhanced germination of barley (Hordeum vulgare L.) using chitooligosaccharide as an elicitor in seed priming to improve malt quality. Biotechnol. Lett. 2016, 38, 1935-1940. [CrossRef]

38. Sikanyika, M.; Aragão, D.; McDevitt, C.A.; Maher, M.J. The structure and activity of the glutathione reductase from Streptococcus pneumoniae. Acta Crystallogr. F 2019, 75, 54-61. [CrossRef]

39. Müller-Schüssele, S.J.; Wang, R.; Gütle, D.D.; Romer, J.; Rodriguez-Franco, M.; Scholz, M.; Buchert, F.; Luth, V.M.; Kopriva, S.; Dörmann, P.; et al. Chloroplasts require glutathione reductase to balance reactive oxygen species and maintain efficient photosynthesis. Plant J. 2020, 103, 1140-1154. [CrossRef]

40. Misra, N.; Gupta, A.K. Effect of salinity and different nitrogen sources on the activity of antioxidant enzymes and indole alkaloid content in Catharanthus roseus seedlings. J. Plant Physiol. 2006, 163, 11-18. [CrossRef] 
41. Adak, S.; Datta, A.K. Leishmania major encodes an unusual peroxidase that is a close homologue of plant ascorbate peroxidase: A novel role of the transmembrane domain. Biochem. J. 2005, 390, 465-474. [CrossRef]

42. Kidwai, M.; Ahmad, I.Z.; Chakrabarty, D. Class III peroxidase: An indispensable enzyme for biotic/abiotic stress tolerance and a potent candidate for crop improvement. Plant Cell Rep. 2020, 39, 1381-1393. [CrossRef]

43. Maria, K.; Yogeshwar, V.D.; Neelam, G.; Madhu, T.; Iffat, Z.A.; Mehar, H.A.; Debasis, C. Oryza sativa class III peroxidase (OsPRX38) overexpression in Arabidopsis thaliana reduces arsenic accumulation due to apoplastic lignification. J. Hazard. Mater. 2018, 362, 383-393.

44. Nabaei, M.; Amooaghaie, R. Melatonin and nitric oxide enhance cadmium tolerance and phytoremediation efficiency in Catharanthus roseus (L.) G. Don. Environ. Sci. Pollut. Res. 2020, 27, 6981-6994. [CrossRef]

45. Trist, B.; Hilton, J.B.; Crouch, P.J.; Hare, D.J.; Double, K.L. Superoxide dismutase 1 in health and disease: How a front-line antioxidant becomes neurotoxic. Angew. Chem. Int. Ed. 2021, 60, 9215-9246. [CrossRef]

46. Khataee, E.; Karimi, F.; Razavi, K. Alkaloids production and antioxidant properties in Catharanthus roseus (L.) G. Don. shoots and study of alkaloid biosynthesis-related gene expression levels in response to methyl jasmonate and putrescine treatments as eco-friendly elicitors. Biol. Futura 2019, 70, 38-46. [CrossRef]

47. Liaqat, F.; Eltem, R. Chitooligosaccharides and their biological activities: A comprehensive review. Carbohydr. Polym. 2018, 184, 243-259. [CrossRef]

48. Verma, P.; Mathur, A.K.; Khan, S.A.; Verma, N.; Sharma, A. Transgenic studies for modulating terpenoid indole alkaloids pathway in Catharanthus roseus: Present status and future options. Phytochem. Rev. 2015, 16, 19-54. [CrossRef]

49. Liu, J.Q.; Cai, J.J.; Wang, R.; Yang, S.H. Transcriptional regulation and transport of terpenoid indole alkaloid in Catharanthus roseus: Exploration of new research directions. Int. J. Mol. Sci. 2016, 18, 53. [CrossRef]

50. Sharma, A.; Verma, P.; Mathur, A.; Mathur, A.K. Overexpression of tryptophan decarboxylase and strictosidine synthase enhanced terpenoid indole alkaloid pathway activity and antineoplastic vinblastine biosynthesis in Catharanthus roseus. Protoplasma 2018, 255, 1281-1294. [CrossRef]

51. Liu, Y.L.; Patra, B.; Singh, S.K.; Paul, P.; Zhou, Y.; Li, Y.Q.; Wang, Y.; Pattanaik, S.; Yuan, L. Terpenoid indole alkaloid biosynthesis in Catharanthus roseus: Effects and prospects of environmental factors in metabolic engineering. Biotechnol. Lett. 2021, 43, 2085-2103. [CrossRef]

52. Liu, J.Q.; Gao, F.Y.; Ren, J.S.; Lu, X.J.; Ren, G.J.; Wang, R. A novel AP2/ERF transcription factor CR1 regulates the accumulation of vindoline and serpentine in Catharanthus roseus. Front. Plant Sci. 2017, 8, 2082. [CrossRef] [PubMed]

53. Khataee, E.; Karimi, F.; Razavi, K. Different carbon sources and their concentrations change alkaloid production and gene expression in Catharanthus roseus shoots in vitro. Funct. Plant Biol. 2020, 48, 40-53. [CrossRef] [PubMed]

54. Pandey, S.S.; Singh, S.; Babu, C.S.V.; Shanker, K.; Srivastava, N.K.; Shukla, A.K.; Kalra, A. Fungal endophytes of Catharanthus roseus enhance vindoline content by modulating structural and regulatory genes related to terpenoid indole alkaloid biosynthesis. Sci. Rep. 2016, 6, 26583. [CrossRef]

55. Zhu, W.; Yang, B.X.; Komatsu, S.; Lu, X.P.; Li, X.M.; Tian, J.K. Binary stress induces an increase inindole alkaloid biosynthesis in Catharanthus roseus. Front Plant Sci. 2015, 6, 00582. [CrossRef] [PubMed]

56. Pan, Y.J.; Liu, J.; Guo, X.R.; Zu, Y.G.; Tang, Z.H. Gene transcript profiles of the TIA biosynthetic pathway in response to ethylene and copper reveal their interactive role in modulating TIA biosynthesis in Catharanthus roseus. Protoplasma 2015, 252, 813-824. [CrossRef] [PubMed]

57. Available online: https://www.jinke-chitin.com/ (accessed on 27 February 2022).

58. Pérez-Harguindeguy, N.; Díaz, S.; Garnier, E.; Lavorel, S.; Poorter, H.; Jaureguiberry, P.; Bret-Harte, M.S.; Cornwell, W.K.; Craine, J.M.; Gurvich, D.E.; et al. New handbook for standardised measurement of plant functional traits worldwide. Aust. J. Bot. 2013, 61, 167-234. [CrossRef]

59. Karimi, F.; Khataee, E. Aluminum elicits tropane alkaloid production and antioxidant system activity in micropropagated Datura innoxia plantlets. Acta Physiol. Plant. 2012, 34, 1035-1041. [CrossRef]

60. Soltani, N.; Nazarian-Firouzabadi, F.; Shafeinia, A.; Sadr, A.S.; Shirali, M. The expression of Terpenoid Indole Alkaloid (TIAs) pathway genes in Catharanthus roseus in response to salicylic acid treatment. Mol. Biol. Rep. 2020, 47, 7009-7016. [CrossRef]

61. Livak, K.J.; Schmittgen, T.D. Analysis of relative gene expression data using real-time quantitative PCR and the $2^{-\Delta \Delta C T}$ method. Methods 2001, 25, 402-408. [CrossRef] 